NBER WORKING PAPER SERIES

\title{
ASSESSING, MANAGING AND FINANCING EXTREME EVENTS: DEALING WITH TERRORISM
}

\author{
Howard Kunreuther \\ Erwann Michel-Kerjan \\ Beverly Porter \\ Working Paper 10179 \\ http://www.nber.org/papers/w10179
NATIONAL BUREAU OF ECONOMIC RESEARCH
1050 Massachusetts Avenue
Cambridge, MA 02138 \\ December 2003
}

\begin{abstract}
We are grateful to Elisabeth Abrams, Jim Ament, Neil Doherty, Martin Feldstein, Geoff Heal, Carl Hedde, Paul Kleindorfer, Christian Gollier, Patricia Grossi, Burkhard Pedell, Jack Seaquist, Kent Smetters and Gordon Woo for valuable comments on various drafts of this paper. Kunreuther and Michel-Kerjan acknowledge financial support from Radiant Trust, Lockheed Martin and the Institut Veolia. The views expressed herein are those of the authors and not necessarily those of the National Bureau of Economic Research.
\end{abstract}

(C2003 by Howard Kunreuther, Erwann Michel-Kerjan, and Beverly Porter. All rights reserved. Short sections of text, not to exceed two paragraphs, may be quoted without explicit permission provided that full credit, including (C) notice, is given to the source. 
Assessing, Managing and Financing Extreme Events: Dealing with Terrorism Howard Kunreuther, Erwann Michel-Kerjan, and Beverly Porter

NBER Working Paper No. 10179

December 2003

JEL No. G22, G28, D80

\section{ABSTRACT}

This paper discusses new challenges we face with terrorism as a catastrophic risk by focusing on risk assessment, risk management as well as risk financing issues. The special characteristics of terrorism compared with major natural hazards call for the development of public-private partnerships, as recognized in November 2002 when the Terrorism Risk Insurance Act of 2002 (TRIA) was passed. This paper shows, however, that the temporary insurance system established by TRIA is neither a complete answer nor a definitive one. It raises fundamental questions for U.S. insurers as to how they will estimate the risk in order to set premiums for terrorist coverage that they now must offer to their clients. We discuss some of the most recent developments of terrorism models for helping insurers and reinsurers assess the premiums they should charge and how much coverage they can assume as well as for firms to better understand their exposure.

Since the passage of TRIA, the current level of demand for insurance coverage has remained low and we discuss some factors that may contribute to it. After presenting alternative foreign public-private partnerships and discussing the potential role for terrorist catastrophe bonds, we provide some features of a more sustainable program for terrorism insurance in the U.S. after December 31, 2005.

\begin{tabular}{|c|c|c|}
\hline Howard Kunreuther & Erwann Michel-Kerjan & Beverly Porter \\
\hline The Wharton School & The Wharton School & AIR Worldwide Corporation \\
\hline Center for Risk Management & Center for Risk Management & 101 Huntington Avenue \\
\hline Jon M Huntsman Hall, Suite 500 & Jon M Huntsman Hall, Suite 500 & Boston, MA 02199 \\
\hline 3730 Walnut Street & 3730 Walnut Street & bporter@air-worldwide.com \\
\hline $\begin{array}{l}\text { Philadelphia, PA 19104-6340 } \\
\text { and NBER }\end{array}$ & $\begin{array}{l}\text { Philadelphia, PA 19104-6340 } \\
\text { erwannmk@wharton.upenn.edu }\end{array}$ & \\
\hline
\end{tabular}




\section{INTRODUCTION}

The nature of international terrorism has changed in the 1990s. As studied by several authors, there has been a significant rise in casualties from transnational incidents due to terrorism over the last decade (Hoffman, 1998; Enders and Sandler, 2000). As pointed out by Sandler and Enders (in press), "the events of 11 September with their massive casualties of innocent people of all ages came as no surprise to those of us who study terrorism and warned of an ominous changing nature of transnational terrorism."

Although numerous efforts have been undertaken during the last two years to prevent new attacks on US soil, the economic impact of a successful attack has to be seriously considered. As defined by the White House in July 2002, homeland security is "the concerted effort to prevent attacks, reduce America's vulnerability to terrorism, and minimize the damage and recover from attacks that do occur" (White House, 2002, p.2). Part of that "recovery component" is the need for insurance coverage to provide adequate financial protection to victims of catastrophes. Those systems must be adequately designed to assure business and social continuity of the country in case of major attacks.

Prior to September 11, 2001 (9/11) terrorism coverage in the United States was included in most standard commercial policy packages without considering the risk associated with these events. The private insurance market had functioned effectively in the U.S. because losses from terrorism had historically been small and, to a large degree, uncorrelated. Attacks of a domestic origin were isolated and carried out by groups or individuals with disparate agendas.

None of these events created major economic disruption nor produced many casualties. The 1993 bombing of the World Trade Center (WTC) killed 6 people and caused $\$ 725$ million of insured damages (Swiss Re, 2002-a). The Oklahoma City bombing of 1995 , which killed 168 people, had been the most damaging terrorist attack on domestic soil, but the largest losses were to federal property and employees that were covered by the government.

The analogy to protection against natural hazards is instructive in this regard. The insured losses from Hurricane Andrew in 1992 and the Northridge Earthquake in 1994 led insurers and reinsurers to pay more attention to the catastrophic potential of natural disasters. Some insurers were forced to declare insolvency due to these events. Those that survived began to rethink the ways they were doing business. Many of them turned to catastrophe models for guidance.

Insurers and reinsurers did not have to pay close attention to their potential losses from terrorism in the United States prior to 9/11. The terrorist attacks of September 11, 2001 
killed nearly 3,050 people $^{1}$ and inflicted damage currently estimated at nearly $\$ 80$ billion, about half of which was insured ${ }^{2}$; i.e. the most costly event in the history of insurance (Swiss Re, 2002-a). Commercial property, workers' compensation, life, health, disability, aircraft hull, and general liability lines each suffered catastrophic losses. More specifically, insured business interruption losses were estimated at $\$ 11$ billion, workers' compensation at $\$ 2$ billion, and life insurance at $\$ 2.7$ billion. The insured property losses at the WTC were estimated at $\$ 3.5$ billion, aviation liability also at $\$ 3.5$ billion and other liability costs reimbursed by insurers/reinsurers at $\$ 10$ billion (Hartwig, 2002).

Hence, this event confronted the insurance industry with an entirely new loss dimension. Reinsurers, who were liable for the lion's share of the claims, were for the most part unwilling to renew coverage and the few who marketed policies charged extremely high rates for very limited protection. Insurers unable to obtain reinsurance, or to raise sufficient capital either internally or from the capital markets, scrambled by offering policies that explicitly excluded terrorism coverage.

The lack of available terrorist coverage delayed or prevented certain projects from going forward due to concerns by lenders or investors. For example, the U.S. General Accounting Office noted several cases of deals that could not be completed and a construction project that could not be started because the firms could not find terrorism coverage at prices they could afford (U.S. General Accounting Office 2002 pp.11-14).

The larger question being debated today is whether terrorism is an insurable risk and, if so, how will it be covered. That is, can insurers offer coverage at a premium at which buyers are willing to purchase protection? If so, how does one go about determining that price? What are the chances of another terrorist event occurring? How frequently are such events likely to occur and how severe are they likely to be in terms of insured loss?

Spectacular as were the losses at the WTC and the Pentagon, do they represent the worst-case scenario? Probably not, if the predictions of some concerning a possible chemical or biological attack become a reality. Since the start of the war in Iraq in March 2003, the U.S. government has issued clear warnings that additional terrorist attacks are likely. Several terrorist attacks have indeed occurred that have been linked to Al Qaeda, including the deadly explosion at a nightclub in Bali that killed close to 200 in October 2002. Some have suggested that the resolution of the war in Iraq will diminish the threat of future attacks. Others argue the opposite. What is unarguable is that the uncertainties associated with terrorism risk are considerable.

In the field of risk management, catastrophic risks present very specific challenges to be dealt with by a wide range of stakeholders: insured and not insured citizens and firms, insurance and reinsurance industry, financial markets, government and policymakers. The general question that emerged in the 1990's along with the unprecedented dimension of losses due to major natural disasters was: how does one assess and manage risk associated with extreme events that are characterized by a low probability of occurrence but which, if

\footnotetext{
${ }^{1}$ This number represents victims of the attacks in New York, Washington, DC and Pennsylvania as well as among teams of those providing emergency service.

${ }^{2}$ The exact amount is still evolving and can also differ from a study to another depending on what types of loss are considered.
} 
they occur, are of high impact? This paper focuses on the new challenges we face with terrorism as a catastrophic risk. ${ }^{3}$

The paper is organized as follows. The next section discusses the nature of terrorism as a catastrophic risk, whether that risk is insurable and differences between the risk of terrorism and that of natural disasters as well as the need for public-private partnerships to cover the risk. Section 3 describes the nature of insurance protection under the Terrorism Risk Insurance Act (TRIA) of 2002 as well as supply and demand for terrorism coverage and suggests why the current demand for terrorism coverage has been low since TRIA was passed. Section 4 discusses the recent development in modeling the terrorist risk in assisting insurers and reinsurers to assess the premiums they should charge and how much coverage they can assume. This section also discusses how terrorist models are now being used to establish insurance rates nationwide. After discussing the potential role of terrorist catastrophe bonds and presenting alternative foreign public-private partnerships in Section 5, the paper concludes with directions for future research.

\section{IS TERRORISM AN INSURABLE RISK?}

Consider a standard insurance policy whereby premiums are paid at the start of a given time period to cover losses during this interval. Two conditions must be met before insurance providers are willing to offer coverage against an uncertain event. Condition 1 is the ability to identify and quantify, or estimate at least partially, the chances of the event occurring and the extent of losses likely to be incurred. Condition 2 is the ability to set premiums for each potential customer or class of customers. If Conditions 1 and 2 are both satisfied, a risk is considered to be insurable. But there may still be no market-clearing price for the coverage that will be profitable for the insurer. In other words, it may be impossible to specify a rate for which there is sufficient demand and incoming revenue to cover the development, marketing, operating and claims processing costs of the insurance and yield a net positive profit over a prespecified time horizon (e.g. 5 years). In such cases the insurer will opt not to offer coverage against this risk.

\subsection{Satisfying the Insurability Conditions}

To satisfy Condition 1 estimates must be made of the frequency of specific events and the extent of losses likely to be incurred. Such estimates can use historical data and/or scientific analyses as well as data on what experts know and do not know about a particular risk to construct a loss exceedance probability (EP) curve that depicts the probability that a certain level of loss will be exceeded during some prespecified time period (e.g., 2004) ${ }^{4}$.

It is considerably more challenging to construct an EP curve for terrorist activities than it is for natural disasters for several reasons. For one thing it is much more difficult to determine the probability that a terrorist attack will occur because of our extremely limited

\footnotetext{
${ }^{3}$ Several other authors have been working on related issues over the past two years, see Cummins and Doherty (2002), Jaffee and Russell (2002), Lelain et al. (2002), Swiss Re (2002-b).

${ }^{4}$ It is not necessary, however, to have a precise estimate of the probability for a risk to be covered by insurance (Eeckhoudt and Gollier, 1999; Gollier, 2000). For example, space insurance coverage began in 1965 -by Lloyd's of London- despite the lack of historical data and the difficulty of calculating the risk of failure. Lloyd's covered the discovery of the Loch Ness monster in 1973. In 2001, potential attacks by the Yeti for travelers in the Himalaya Mountains have been covered too (Godard et al., 2002).
} 
data on these events, particularly if one is restricting the sample space to a particular geographical area such as the United States. Furthermore a potential target that may appear to have a high likelihood of attack, such as a trophy building, may also have a high level of protection and security which makes it less likely to be chosen by terrorists (Woo, 2002). It is easier to construct estimates of the losses by constructing scenarios of different types of events that could occur as illustrated in Section 4.

With respect to Condition 2, the considerable ambiguity associated with the terrorist risk implies that insurers will want to charge a much higher premium than if they had more precise estimates of the probability and associated losses. (Kunreuther et al., 1995). If the capacity of the industry is reduced due to a decrease in surplus from large losses and the reluctance of investors to provide sufficient new capital, then premiums will rise due to a shortage in supply. The situation will be exacerbated if the recent losses from a catastrophic risk trigger an increase in demand for coverage, as was the case after September $11^{\text {th }}$.

Both terrorist activities and natural disasters have the potential to create extreme losses, thereby posing limitations for the insurability of the risk. Because of this shared characteristic, one may be tempted to draw parallels between the two without paying sufficient attention to their crucial differences. These differences include: availability of historical data ${ }^{6}$, ambiguity of the risk, information sharing, the potential to influence the probability of an event, and differences in the impact of mitigation measures on future losses. The differences are summarized in Table 1. Two features of the terrorism risk - information sharing and dynamic uncertainty - raise some challenges for the private sector in providing insurance protection without some type of partnership with the public sector.

\subsection{Information Sharing and Dynamic Uncertainty}

Information is currently shared differently for terrorism than for natural hazards. In the case of natural hazards, new scientific information on the risk is public knowledge so that insurers, citizens or businesses at risk and public sector agencies all can have access to this information. With respect to terrorism, whatever data exists on possible attacks or current threats is normally kept secret by government agencies for national security reasons.

One justification for government intervention in insurance markets relates to problems of asymmetric information between buyers and sellers (e.g., adverse selection). In the case of terrorism there is symmetry of non-information on the risk between insureds and insurers where government is the most informed party ${ }^{7}$. This information issue constitutes a notable feature of terrorism as catastrophic risk. (See Table 1).

\footnotetext{
${ }^{5}$ This was also the case in California following the Northridge earthquake of 1994. Insurers contended that they could not risk selling more earthquake coverage at the current regulated rates. This led to the formation of a state-run earthquake insurance company - the California Earthquake Authority. (Roth, Jr. 1998); see also Kleindorfer and Kunreuther (1999) and Grace et al. (2003).

${ }^{6}$ Terrorism is of course not a new risk per se. However, as we mentioned in the introduction, the nature of terrorist activities has been seriously changing for the past decade: new groups appeared, with new expectations. As a result of that, historical data may be poorly helpful to analyze emerging threats.

${ }^{7}$ Of course, that may constitute a real limitation of the development of an insurance market if government determined the price of terrorism coverage, which is currently not the case in the US.
} 
Table 1. Natural Hazards versus Terrorism Risks

\begin{tabular}{|c|c|c|}
\hline & $\begin{array}{c}\text { Natural Hazards } \\
\text { Potential catastrophic losses }\end{array}$ & $\begin{array}{c}\text { Terrorism Risks } \\
\text { Potential catastrophic losses }\end{array}$ \\
\hline Historical Data & $\begin{array}{l}\text { Some historical data: } \\
\text { Record of several extreme events already } \\
\text { occurred. }\end{array}$ & $\begin{array}{l}\text { No historical data: } \\
9 / 11 \text { events were the first terrorist } \\
\text { attacks worldwide with such a huge } \\
\text { concentration of victims and insured } \\
\text { damages. }\end{array}$ \\
\hline $\begin{array}{l}\text { Risk of } \\
\text { Occurrence }\end{array}$ & $\begin{array}{l}\text { Risk reasonably well-specified: } \\
\text { Well-developed models for estimating } \\
\text { risks based on historical data and } \\
\text { experts' estimates. }\end{array}$ & $\begin{array}{l}\text { Considerable ambiguity of risk: } \\
\text { Terrorists can purposefully adapt their } \\
\text { strategy (target, weapons, time) } \\
\text { depending on their information on } \\
\text { vulnerabilities; dynamic uncertainty. }\end{array}$ \\
\hline Geographic Risk & $\begin{array}{l}\text { Specific areas at risk: } \\
\text { Some geographical areas are well known } \\
\text { for being at risk (e.g., California for } \\
\text { earthquakes or Florida for hurricanes). }\end{array}$ & $\begin{array}{l}\text { All areas at risk: } \\
\text { Some cities may be considered riskier } \\
\text { than others (e.g., New York City, } \\
\text { Washington), but terrorists may attack } \\
\text { anywhere, any time. }\end{array}$ \\
\hline Information & $\begin{array}{l}\text { Information sharing: } \\
\text { New scientific knowledge on natural } \\
\text { hazards can be shared with all the } \\
\text { stakeholders. }\end{array}$ & $\begin{array}{l}\text { Asymmetry of information: } \\
\text { Governments keep secret new } \\
\text { information on terrorism for obvious } \\
\text { national security reasons. }\end{array}$ \\
\hline Event Type & $\begin{array}{l}\text { Natural event: } \\
\text { To date no one can influence the } \\
\text { occurrence of an extreme natural event } \\
\text { (e.g., an earthquake). }\end{array}$ & $\begin{array}{l}\text { Resulting event: } \\
\text { Governments can influence terrorism } \\
\text { (e.g., foreign policy; international } \\
\text { cooperation; national security } \\
\text { measures). }\end{array}$ \\
\hline $\begin{array}{c}\text { Preparedness } \\
\text { and Prevention }\end{array}$ & $\begin{array}{l}\text { Insureds can invest in well-known } \\
\text { mitigation measures. }\end{array}$ & $\begin{array}{l}\text { Weapons and configurations are } \\
\text { numerous. Negative externalities of } \\
\text { self-protection effort; substitution } \\
\text { effect in terrorist activity. } \\
\text { Insureds may have difficulty in } \\
\text { choosing measures to reduce } \\
\text { consequences of an attack; } \\
\text { Federal agencies may be in a better } \\
\text { position to develop more efficient } \\
\text { global mitigation programs. }\end{array}$ \\
\hline $\begin{array}{l}\text { Catastrophe } \\
\text { Modeling }\end{array}$ & $\begin{array}{l}\text { Developed in late 1980's and early } \\
\text { 1990's. }\end{array}$ & $\begin{array}{l}\text { The first models were developed in } \\
2002 \text {. }\end{array}$ \\
\hline
\end{tabular}

A principal terrorist goal is to destabilize a region or country by attacking certain targets that disrupt normal activities and by creating fear. Since terrorists will adapt their strategy as a function of their resources and their knowledge of the vulnerability of the entity they are attacking, the nature of the risk changes over time leading to dynamic uncertainty. This feature of the risk reflects an important difference from natural hazards. Damage due to a future large-scale earthquake in Los Angeles can be reduced through adoption of mitigation measures; however, it is currently not possible to influence the occurrence of the earthquake 
itself. Terrorism risk, on the other hand, will change depending on two complementary strategies to combat terrorism, which thus becomes a mixed public-private good (Trajtenberg, 2003). The first entails protective measures adopted by those at risk with potential negative externalities on the other targets. The second consists of actions taken by the government to enhance general security and reduce the probability that a terrorist attack will occur.

Indeed, another aspect of terrorism is the negative externality stemming from selfprotection on the risks faced by others. Keohane and Zeckhauser (2002) analyze the relationships between the behavior of potential victims and the behavior of terrorists. They point out that establishing publicly observable protective measures against a given mode of attack on a specific building should reduce the probability of an attack against it because the marginal benefit of the attack (i.e., the likelihood of success) as perceived by the terrorist group decreases. However, shielding that building makes an attack on an uprotected structure more likely. This type of dynamic interdependency reduces the social benefit from protection by individual building owners. For this reason federal agencies may be in a better position to develop global mitigation programs and hence internalize these externalities.

Dealing with terrorism and governmental risk management policies, a substitution effect (Sandler, Tschirhart, Cauley, 1983) also has to be considered when evaluating the effectiveness of specific policies aimed at curbing terrorism. For example, the decision to install weapon detectors in airports may reduce skyjackings but also encourage terrorists to adopt other modes of attacks (e.g., assassination attempts). Hence, the measure of effectiveness must take into account both direct effects and indirect ones: a policy can be effective in thwarting a specific type of terrorist event but not in curbing terrorism per se (Enders and Sandler, 1993; Cauley and Im, 1988).

These features of terrorism raise the question as to how the government and the insurance industry can work together in providing protection and reducing future losses from these risks. The need for public-private partnerships was recognized in November 2002 when the Terrorism Risk Insurance Act of 2002 (TRIA) was passed. TRIA raises fundamental questions for U.S. insurers as to how they will estimate the risk in order to set premiums for terrorist coverage that they now must offer to their clients.

\section{TERrorism Risk InSURANCE ACT (TRIA) OF 2002}

In the aftermath of the $9 / 11$ attacks many insurers warned that another event of comparable magnitude could do irreparable damage to the industry. Furthermore, they contended that the uncertainties surrounding terrorism risk were so significant that it was, in fact, an uninsurable risk.

By early 2002, 45 States permitted insurance companies to exclude terrorism from their policies (Brown, Kroszner and Jenn, 2002). On the one-year anniversary of the $9 / 11$ attacks, the U.S. remained largely uncovered (Hale, 2002). The President and the U.S. Congress viewed such a situation as unsustainable. If the country suffered future attacks it would inflict severe financial consequences on affected businesses deprived of insurance. TRIA, which provides for up to $\$ 100$ billion of terrorism insurance, was passed by Congress in November 2002 and signed into law by President Bush the next month. 


\subsection{Public-private Risk Sharing under TRIA}

While the passage of TRIA may have been welcome news for commercial enterprises $^{8}$, it was a mixed blessing for insurers who were obligated to offer an insurance policy against terrorism to all their clients and the insured has the option of refusing the coverage. Insured losses from commercial lines of insurance as well as business interruption due to an attack are covered under TRIA only if the event is certified by the U.S. Treasury Secretary as an "act of terrorism", that is, as having been carried out by foreign persons or interests 9 and only for losses higher than $\$ 5$ million.

Under TRIA's three-year term (ending December 31,2005$)^{10}$, there is a specific risksharing arrangement between the federal government and insurers ${ }^{11}$ that operates in the following manner. First, the federal government is responsible for paying $90 \%$ of each insurer's primary property-casualty losses during a given year above the applicable insurer deductible (ID), up to a maximum of $\$ 100$ billion. The insurer's deductible is determined as a percentage of the direct commercial property and casualty earned premiums of each insurer the preceding year. The percentage varies over the three-year operation of TRIA: $7 \%$ in $2003,10 \%$ in 2004 and $15 \%$ in 2005. The federal government does not receive any premium for providing this coverage.

Second, if the insurance industry suffers terrorist losses that require the government to cover part of the claim payments, then these outlays will be partially recouped ex post through a mandatory policy surcharge. That surcharge is applied to all property and casualty insurance policies whether or not the insured has purchased terrorist coverage, with a maximum of $3 \%$ of the premium charged under that policy. The federal government will pay for insured losses above specific insurance marketplace retention amount (MR) as depicted in Figure 1. That amount evolves as follows: $\$ 10$ billion in 2003, $\$ 12.5$ billion for 2004 and $\$ 15$ billion for 2005 .

\subsection{Some Illustrative Scenarios}

To illustrate how TRIA operates, consider an "act of terrorism" occurring in 2004 in the U.S. Suppose that N insurance companies cover all terrorist losses and that the premiums for commercial and worker's compensation lines of business for those $\mathrm{N}$ insurers was $\$ 40$ billion in 2003 (subject to the deductible). As each insurer has to pay its deductible (10\% in 2004 ), the total insurers' deductible is equal to $\$ 4$ billion. Let $S_{\max }$ be the maximum ex post surcharge that the government can levy for the year 2004. Now consider three different scenarios with increasing levels of insured losses.

Scenario A. The insured losses are $\$ 500$ million.

That amount is below the total insurers' deductible, $\$ 4$ billion, so the insurers cover the entire amount of the losses. The federal government pays nothing.

\footnotetext{
${ }^{8}$ According to a recent study by the Council of Insurance Agents and Brokers (CIAB), $85 \%$ of insurance brokers who responded estimated that terrorism was more available in the market in June 2003 than it was in January 2003 (CIAB, July 2003).

${ }^{9}$ An event like the Oklahoma City bombings would not be covered under TRIA.

${ }^{10}$ The act expires on December 31, 2004, but may be extended through 2005.

${ }^{11}$ Reinsurers are not part of TRIA but can provide coverage to insurers against their losses from terrorist attacks.
} 
Figure 1. Loss sharing under TRIA

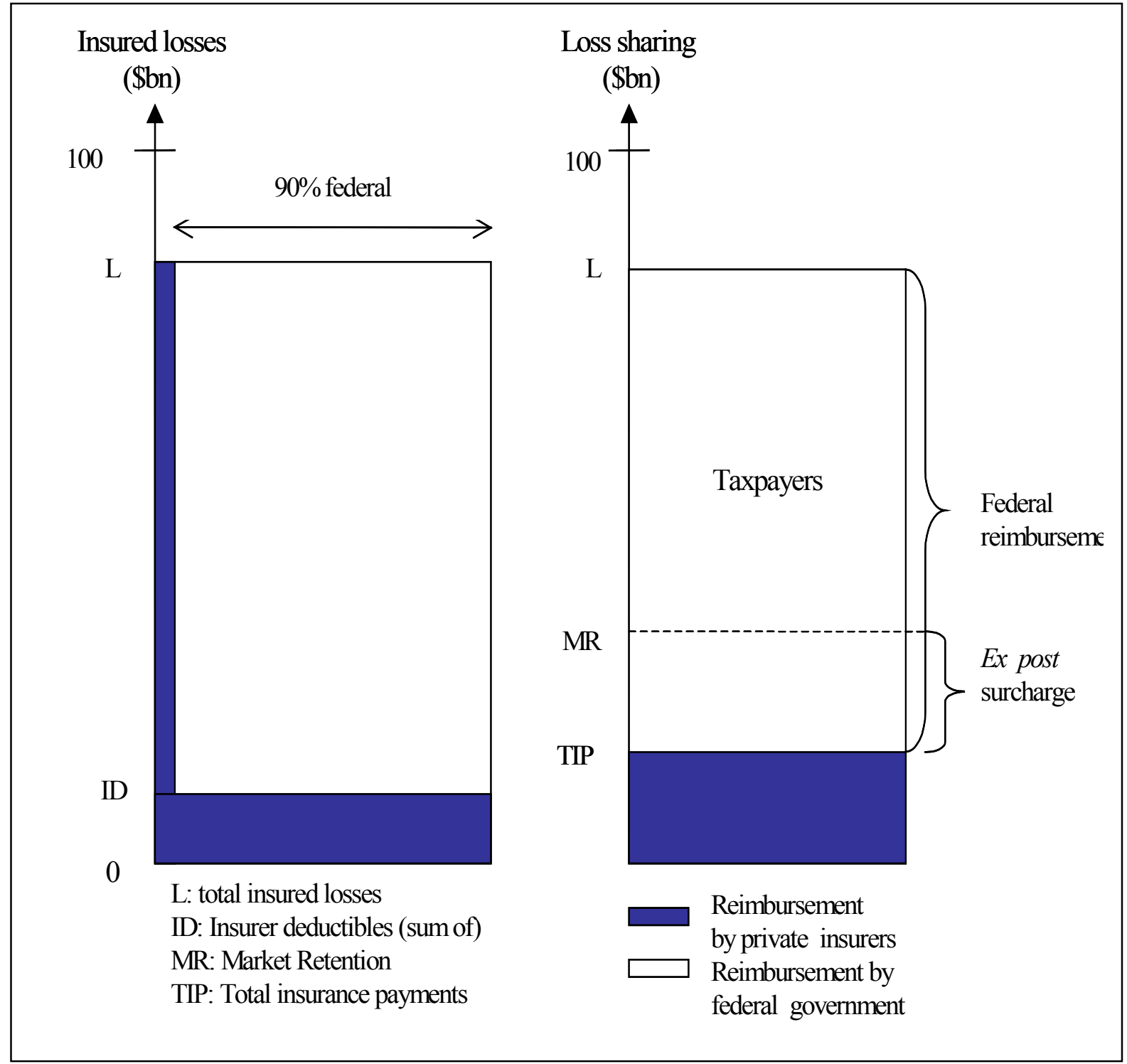

Scenario B. The insured losses are $\$ 5$ billion.

The insured losses are above the insurers' deductible. Insurers would have to pay $\$ 4.1$ billion: the total deductible (i.e., $\$ 4$ billion) as well as $10 \%$ of the remaining insured losses (i.e., $10 \%$ of $\$ 1$ billion). The federal government pays $90 \%$ of $\$ 1$ billion (i.e., $\$ 0.9$ billion). As the $\$ 5$ billion losses are lower than the $\$ 12.5$ billion market retention, the government can be reimbursed by levying the surcharge $S_{\max }$. Under that scenario, $S_{\max }$ covers all federal payments ${ }^{12}$. After the surcharge is levied, the insurers and insured cover the entire claims payments; the government pays nothing.

\footnotetext{
${ }^{12}$ As the surcharge is applied to all property and casualties insurance policies and not only to those covered by the $\mathrm{N}$ insurers, $\mathrm{S}_{\max }$ is, by definition, higher than $3 \%$ of $\$ 40$ billion in that example; i.e. higher than $\$ 1.2$ billion.
} 
Scenario $C$. The insured losses are $\$ 20$ billion.

Here again, insurers would have to pay the total deductible (i.e., $\$ 4$ billion) as well as $10 \%$ of the remaining amount of insured losses ( $10 \%$ of 16 billion), i.e. a total $\$ 5.6$ billion ${ }^{13}$. The federal government pays $90 \%$ of the remaining amount of $\$ 16$ billion, i.e. $\$ 14.4$ billion $^{14}$. The government will recoup the difference between the $\$ 12.5$ billion representing the insurance industry aggregate threshold for 2004 and the $\$ 5.6$ billion that private insurers paid out; i.e. a surcharge levied ex post against policyholders of $\$ 6.9$ billion. ${ }^{15}$ In this case the government pays $\$ 7.5$ billion of the losses ${ }^{16}$ with the remainder covered by insurers providing terrorist coverage and all the property and casualty policyholders. Table 2 summarizes these three scenarios.

Table 2. TRIA under three simple scenarios

\begin{tabular}{|c|c|c|c|}
\hline $\begin{array}{c}\text { Insured losses } \\
\text { (\$ Billion) }\end{array}$ & $\begin{array}{c}\text { Losses retained by the } \\
\text { N insurers }\end{array}$ & $\begin{array}{c}\text { Reimbursement by } \\
\text { federal government }\end{array}$ & $\begin{array}{c}\text { Via 2004 surcharge } \\
\text { (policyholders) }\end{array}$ \\
\hline .5 & .5 & 0 & 0 \\
\hline 5 & $\begin{array}{c}4.1 \\
(4+0.1 * 1)\end{array}$ & $\begin{array}{c}.9 \\
(0.9 * 1)\end{array}$ & $\begin{array}{c}.9 \\
\text { Min }(\mathrm{S} ; 0.9)\end{array}$ \\
\hline 20 & 5.6 & 14.4 & $\operatorname{Min}\left(\mathrm{S}_{\max } ; 6.9\right)$ \\
$(4+0.1 * 16)$ & $(0.9 * 16)$ & $(6.9=12.5-5.6)$ \\
\hline
\end{tabular}

\subsection{Insurance supply}

Under TRIA, insurers are required to offer all their policyholders terrorist coverage for commercial property, commercial casualty and workers' compensation ${ }^{17}$ lines. This terrorism coverage must not differ from non-terrorism coverage and the insured has the option of refusing the coverage. Companies were given 90 days after TRIA was enacted on November 26, 2002 to develop and disclose to policyholders new premiums and coverage terms. Many insurance companies found themselves in the situation of having to set a price for a risk they would prefer not to write. Although their exposure to terrorism risk was much reduced through the public-private partnership created by TRIA, it is still significant.

Over the course of the next 90 days, insurance companies followed a variety of strategies. Some determined that their exposures were not in high-risk locations and chose to leave existing premiums unchanged. Others, particularly those with portfolio concentrations in major metropolitan areas deemed at high risk, such as New York, Washington, DC, Chicago and San Francisco, set very high premiums.

\footnotetext{
${ }^{13}$ Under such a scenario and if we assume the total premiums received by these $\mathrm{N}$ insurers remain the same in 2002, 2003 and 2004, these $\mathrm{N}$ insurers would have paid $\$ 4.52$ billion in 2003 and they would pay $\$ 7.4$ billion in 2005 .

${ }^{14}$ Under the same assumption, federal government would have paid $\$ 15.48$ billion in 2003 and it would pay $\$ 12.6$ billion in 2005 .

${ }^{15}$ If that amount is greater than the $3 \%$ threshold $\left(\mathrm{S}_{\max }\right)$, the surcharge will be levied over several years.

${ }^{16}$ To be compared with $\$ 10$ billion in 2003 and \$5 billion in 2005 .

${ }^{17}$ Terrorist coverage for workers' compensation covers both terrorist attacks and acts of war.
} 


\subsection{Low insurance demand}

TRIA is designed to provide adequate reimbursements and indemnification to victims of major terrorist attacks and to assure social and economic continuity of the country should a terrorist attack occurs. The existence of a viable terrorism insurance market is a cornerstone for a system of national preparedness since it impacts on a variety of economic activities. These range from real estate transactions where insurance is normally a condition for a mortgage to investment in cost-effective loss reduction measures that are rewarded by lower premiums or higher coverage limits. Developing a meaningful insurance program requires accurate estimates of the likelihood and consequences of terrorist attacks, thus aiding the process of emergency preparedness and response.

Congress passed TRIA in November 2002 partly for these reasons and also because there was a huge demand for coverage by firms during the year following 9/11 with limited coverage available at an affordable price. The expectation was that TRIA would ease insurers concerns about providing coverage and enable buyers at risk to purchase coverage at reasonable prices.

Although insurers are now required to offer terrorism coverage to their commercial clients, they have the freedom to set the premium at whatever level they feel is appropriate. The demand for coverage has been much lower than anticipated even though insurance is now available nationwide (Hsu, 2003; Treaster, 2003). The Council of Insurance Agents and Brokers $(\mathrm{CIAB})^{18}$ undertook the first national survey on the level of demand for terrorist coverage (CIAB, March 2003). At that time, almost half of its members that handle the largest accounts (customers who pay more than $\$ 100,000$ annually in commission and fees to the broker) indicated that less than 1 in 5 of their customers had purchased terrorism insurance. The low demand was even more pronounced for smaller companies (less than $\$ 25,000$ in commission and fees to the broker): $65 \%$ of the brokers indicated that less than 1 in 5 customers were purchasing insurance against terrorism.

According to a recent national survey by the CIAB, $72 \%$ of the brokers indicated that their commercial customers are still not purchasing terrorism insurance coverage (CIAB, July 2003). Even in locations like New York City, the level of demand remains low. The New York-based insurance brokerage firm Kaye Insurance Associates recently surveyed 100 of its clients in the New York area on a series of insurance-related issues, including terrorism insurance. Only $36 \%$ of companies surveyed have bought terrorism insurance (Muto, 2003). If the low level of demand continues this means that an attack similar to the one on the World Trade Center, would very likely have a much more devastating effect on business continuity today than after 9/11. The following factors may be responsible for the lack of interest in insurance coverage.

\section{High Premiums}

Large firms that buy terrorism coverage are now typically paying 20 percent of the standard commercial property/casualty premium, while most small and medium accounts are assessed 10 percent of premium. For large firms in high risk areas such as Manhattan, the cost has been assessed up to 100 percent or more of the standard commercial insurance

\footnotetext{
${ }^{18}$ The council represents the top tier of the nation's insurance brokers who collectively write 80 percent of the commercial property/casualty premiums annually.
} 
premium at the start of 2003 (CIAB, March 2003). While prices have fallen in since then, Manhattan properties are still paying a 20 percent surcharge, according to the Kaye survey.

\section{Credit risk}

Although TRIA limits the potential losses to the insurance industry, some firms are still concerned as to the impact of a large terrorist attack on the solvency of their insurers (i.e., credit risk). They consider the case where insurers may not be able to meet their obligations if a catastrophe occurs as a limitation to terrorism insurance purchase.

\section{Limits in coverage}

Some businesses are concerned not only with "acts of terrorism" certified by the federal government (i.e., terrorist acts sponsored by foreign interests) but also by the prospect of domestic terrorism such as an attack similar to the Oklahoma City bombings in 1995, which are not covered by TRIA. The market for domestic terrorism is still mixed with some insurers offering coverage (sometimes at no cost if the risk is perceived to be low) while other simply excluding it (CIAB, March 2003). In the latter case, businesses may prefer not to buy any terrorist coverage than partial protection.

\section{Behavioral bias}

Another explanation for low demand could be the "it will not happen to me" mentality. Since most businesses have no information on the terrorism risk itself and no new attack has occurred on U.S. soil since 9/11, firms may perceive the chances of another event to be extremely low. This behavior has been well-documented for natural hazards where individuals tend to buy insurance after a disaster occurs and cancel the policy several years later if they have not suffered a loss (Kunreuther, 2002). It is hard to convince them that the best return on an insurance policy is no return at all. In other words, there is a tendency for most people to view insurance as an investment rather than as a form of protection.

Two years after 9/11, the concern with damage from terrorism has assumed a back seat in most people's minds. Today most firms believe that if a terrorist attack occurs it will not happen to them, whereas in the first few months after 9/11 they had the opposite belief. According to the Kaye survey, 68\% of companies that do not have terrorism insurance in New York area responded that the primary reason they have not purchased such coverage is because they didn't consider themselves a terrorism target. At a national level, the CIAB study published in July 2003 indicated that more than $90 \%$ of the brokers said their customers eschew terrorism insurance because they think they don't need it (CIAB, July 2003). These firms consider insurance, even at relatively low premiums, to be a bad investment. If a business were strapped for cash, then it would be more likely to place insurance against terrorism as very low on its priority list. The expectation that government may financially aid affected businesses whether or not they are covered by insurance after a major attack, as illustrated by the airline industry following 9/11, may also contribute to limiting interest in spending money on coverage. 


\subsection{Concluding comments}

There seems to be a large difference in the perception of the seriousness of the terrorist threat by those who are potential buyers of insurance and those who are supplying coverage. Suppliers of terrorism insurance are likely to charge higher premiums than normal because of the large uncertainty surrounding this risk and the possibility of a concentrated loss in a metropolitan area should there be an attack that could lead to insolvency.

In these circumstances TRIA alone will not solve the problem. If one wants to create a market for terrorism insurance, both buyers and sellers need to do a more systematic analysis of the relationship between the price of protection and the implied risk. There is no guarantee that firms will be willing to pay more for coverage or that insurers will greatly reduce their premiums. But there is a much better chance that a larger market for terrorism coverage will emerge than if the status quo is maintained.

The U.S. Treasury Department is required by Congress to undertake studies of the supply and demand for terrorism coverage so that more informed decisions on whether TRIA should be renewed in 2005 may be made. Those studies should contribute to a better understanding of the current level of demand for terrorism insurance as well as to suggest possible improvements in the partnership to create a more stable insurance market should another attack occur. At the same time, many insurers and reinsurers chose to take advantage of newly available tools designed to help them estimate their potential losses and thereby make rational and informed pricing decisions.

Catastrophe modelers, leveraging their considerable experience and expertise in modeling natural hazard events, released the first generation of models to provide insurers with credible estimates of loss across multiple lines from terrorist attacks. The value of such models is in their ability to reduce uncertainty in risk estimates. One effect of that reduced uncertainty would be a lowering of premiums for terrorist insurance.

\section{TERRORISM LOSS ESTIMATION APPROACHES}

Insurance markets function best when losses are relatively small, random and uncorrelated, and when there is an abundance of historical loss data to which statistical techniques can be applied to predict future losses. Conditions are less than ideal when it comes to natural catastrophes as they can be of catastrophic proportion and are often highly correlated. Furthermore, because such extreme events occur infrequently, loss data are relatively scarce, making reliance on traditional actuarial techniques dubious at best.

Using stochastic simulation techniques and a scientific understanding of the physical mechanisms that govern such events, modelers are able to estimate the frequency, spatial distribution and severity of future natural catastrophes. The models incorporate extensive historical databases to develop probability distributions for frequency, location and other physical parameters. By sampling from these distributions to create large stochastic catalogs of simulated events, the models produce distributions of expected losses as reflected in exceedance probability (EP) curves. (Grossi and Kunreuther in press).

Historical data on terrorist attacks, however, is significantly more limited. To the extent they do exist and are available from such sources as the Federal Bureau of Investigation (FBI), the U.S. Department of State, the Center for Defense and International Security Studies (CDISS) and the Central Intelligence Agency (CIA) among others, they may 
not be representative of current threats. Even more important, unlike earthquakes and other natural disasters, whose occurrence has a physical basis that can be understood by scientists, terrorist attacks are a function of the malicious intent of groups of individuals of varying size and varying agendas. The groups themselves come and go and their ability to attract resources in terms of both financial and human capital waxes and wanes as the larger political and/or economic climate changes over time.

As discussed in Section 2, it is clear that the uncertainty surrounding the frequency, location and severity of future terrorist activity is much higher than for natural hazards, making the task of modeling much more complex. In the absence of historical data to which probability distributions can be fit, the models are by necessity more subjective in nature. And while they also produce EP curves, it may be useful to think of these as representing distributions not of expected loss, in the statistical sense, but rather of potential losses. To explore the alternative approaches that modelers have used to overcome the challenges of quantifying terrorism risk, it is useful to begin with a simple model as depicted in Figure 2.

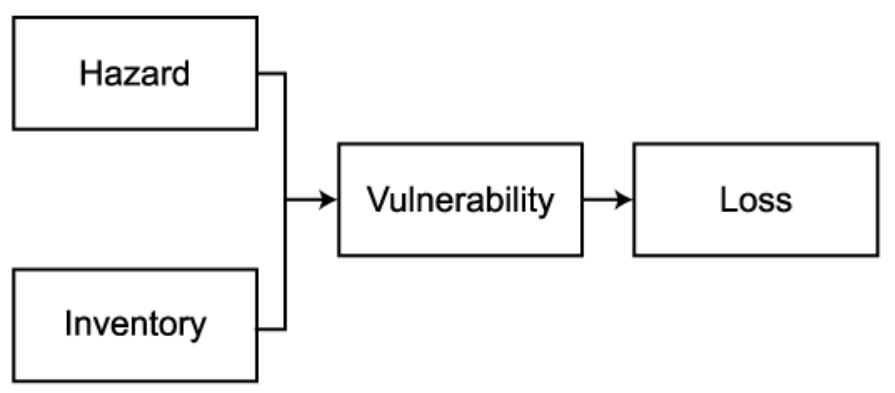

Figure 2. Catastrophe Model Components

\subsection{Estimating Terrorism Hazard}

A terrorism model, like its natural catastrophe counterparts, must first address three basic issues regarding the hazard itself: frequency of occurrence, the most likely locations of future terrorist attacks, and their severity in terms of insured and non-insured loss. In undertaking this analysis, the different potential targets, plus the interdependencies in infrastructures and systems must be taken into account (Pate-Cornell and Guikema, 2002). For example, the loss of electric power or contamination of the water supply could create long-term business interruption risks and require residents in the affected areas to relocate.

The management of international terrorism risks has traditionally relied upon the experience and judgment of a specialist underwriter. For certain individual risks, the advice of security professionals may be sought, and for a portfolio, maximum loss would be carefully capped. However, the overall risk assessment procedure would remain essentially qualitative and subjective. The most basic terrorism risk model is thus one encoded within the working experience of an underwriter, and dependent on his personal expert judgment. To cover rare catastrophic acts of terrorism, beyond the experience of even the most seasoned underwriter, the judgment of external terrorism experts will be invoked. Terrorism risk management would still be firmly judgment-based, but the underwriter would be supported by the greater knowledge and perception of terrorism experts. Recognizing that experts' risk estimates are based on their own set of assumptions and may reflect a set of biases, the challenge is to evaluate these estimates carefully in modeling terrorism risk. 
Terrorism models incorporate the judgment of teams of experts familiar both with limited available data and current trends. These experts will have operational experience in counterterrorism at the highest national and international levels, with many specializing in terrorism threat assessment.

Because each expert is privy to his own sources of intelligence, and has his own security clearances, there is no common database of information upon which all experts can form their judgments. In fact, much of the crucial information is confidential.

\section{Determining Likelihood of Attacks: The Use of Expert Opinion}

The modeling firms use expert opinion in their models to determine the likelihood of attacks but, their collaboration with the scientific community may be based on different approaches. Some modeling firms employ the Delphi method while others utilize a conference of experts to capture and statistically combine various opinions into a useful and cohesive form that can be used to generate probabilities.

The Delphi method This is a well-known and accepted approach developed by the RAND Corporation at the start of the Cold War. Among its first applications was the forecasting of inter-continental warfare and technological change. It was also used by the Applied Technology Council (ATC-13) to derive the damage functions in the first generation of earthquake models.

The Delphi method comprises a series of repeated interrogations, usually administered by questionnaire. Direct interaction between the participants is avoided to preclude any bias resulting from a tendency to "follow the leader". After an initial round of interrogation, subsequent rounds include information from the previous round, presented anonymously. Thus individuals are encouraged to reconsider and, when appropriate, to change their views in light of the replies of other members of the group. They are also asked to assess their own expertise and confidence in their answers. Finally, the results are averaged using these confidence levels as weights. (Adler and Ziglio, 1996).

Experts are asked to weigh in on several aspects of event frequency and intensity: the number of attacks per year, the type of target, the attack mode or weapon type, and finally the specific target of each potential attack. Each of these issues depends in part on the nature of the terrorist organization originating the attack. Critical to the results is the team's operational understanding of the likely terrorist actions in the context of the current state of security countermeasures. Targets and attack methods that were once undefended may now be more vigorously protected by federal homeland security, state and local policy, and private security resources.

While the methodology, if well administered, is highly structured, in the end the outcome is still only opinion, though one that has been summarized statistically, rather than in terms of a majority vote. For complex problems not governed by scientific laws, however, the judgment and intuition of experts in their field is not only an appropriate ingredient in any model, but a critical one.

Conferences of Experts In these conferences, experts can exchange their opinions with all participants. The agenda in those closed meetings can be, for instance, the determination of what kind of weapons a specific terrorist group is more likely to use or what areas/countries are more susceptible to attack. Firms that use this method see the value in having experts share intelligence and other confidential information. When some experts are 
unable to attend the conference, then their judgment can be elicited separately and fed back to others using the Delphi method.

Expert opinions are of course not a definitive answer to the question of determining the probability of an attack using specific weapons against a given potential target, but they allow a better understanding as to how terrorists operate and enable one to refine terrorism models. The lack of historical data makes the use of experts the only way for modelers to determine the likelihood of new attacks by trying to better understand the terrorists' behavior.

Limitations in Using Experts $\quad$ Experts may not always be the best forecasters. As all of them may have knowledge about different aspects of terrorism, some can be much more focused on a given terrorist group and disregard dangers from the other. They can be specialized on a given type of weapon or on a very specific kind of biological or chemical agent. Other experts can be specialized in the political side of terrorism, while others have more experience in its impact on business alone. In other words, the group of experts assembled does not necessarily represent a collective expertise on the subject. Each expert can be accurate within his or her small window of expertise, but the whole group of experts can be wrong about the reality of the global threats; a kind of illusory expertise (Linstone and Turoff, 1975).

Another pitfall is the possible Optimism/Pessimism bias of experts. For instance, if a terrorist attack recently occurred, a natural trend would be to overestimate the likelihood of new attacks in the short run. Conversely, if governmental services arrested leaders of a terrorist group, a natural bias could be to concentrate only on that group and overlook other terrorists so as there may be misconceptions of the likelihood of other attacks.

\section{Identifying Likely Targets and Attack Modes}

Before probabilities of attack can be assigned to individual targets, they must be identified. This is done in conjunction with the modelers' expert teams. Target types will vary depending on the nature and goals of the individual terrorist groups or organizations being modeled. For example, the sorts of targets that the Animal Liberation Front will find attractive, for example, will be quite different from those likely to be chosen by Al Qaeda, not only because of differences in the resources at this group's disposal, but because of its different political agenda ${ }^{19}$.

Once the target types are identified, databases of individual potential targets are developed. Modelers are well positioned to do this, having amassed large databases of building stock with their property values in the course of developing natural catastrophe models. In the case of terrorism, targets (within the U.S.) might include high profile skyscrapers, government buildings, airports, chemical plants, nuclear power plants, dams, major tunnels and bridges, large sport stadiums, major corporate headquarters, marine terminals, and so on. Trophy targets are identified that represent a higher value to the terrorists and therefore, all else being equal, a higher probability of attack. Simulated attacks are perturbed spatially, however, with respect to a given target or within an area, such as a port. Target databases can comprise tens of thousands or even hundreds of thousands of structures.

\footnotetext{
${ }^{19}$ According to Al Qaeda's operational training manuals, that organization's goals include economic disruption and mass casualties. Symbolic targets are also attractive - ones associated with the American way of life or those simply with name recognition (Woo, 2002).
} 
The terrorist group receives value or utility from the damage, or loss, inflicted on his adversary. The expected loss is determined by the probability of success in carrying out the attack and the economic and psychological value of the target. In turn, the probability of success is determined by the amount of resources the terrorist group allocates to the attack, as well as by the amount of resources its opponent allocates to detecting terrorist activity and defending the target. Both parties are constrained by the amount of resources at their disposal and the game becomes essentially one of strategic decisions by the relevant parties about how to deploy those resources, i.e. which targets to attack and with what weapons, and which to defend.

These approaches utilize game theoretic models and simulations of the underlying causality processes that can be parameterized from observational data. An analogy with the war on terrorism may clarify the situation. Military leaders face considerable uncertainty and lack of data in answering the following questions on the battlefield: Where should one attack? When should one attack? What weapons should one use? To shed light on these questions, war gaming has been substantially advanced through the use of mathematical equations, large-scale simulations, and distillations (i.e. relatively simple simulations that capture the salient features of the situation, without trying to model all the details).

In the context of the terrorist risk problem, expert judgment can be elicited through decision conferences at which intelligence and other confidential information can be shared. These decision conferences have provided the knowledge base for the construction of mathematical models of terrorism. Based on this expert opinion one can develop models of interaction based on the principles of game theory. The test of any mathematical risk model is its explanatory and predictive capability. Some game theoretic models predict that as prime targets are hardened, rational terrorists may focus on lesser softer targets to attack (Woo, 2002). This prediction is essentially equivalent to the statement made by the CIA director, George Tenet, in his prophetic unclassified testimony of February 7, 2001, (prior to 9/11) when he said: "as security is increased around government and military facilities, terrorists are seeking out softer targets that provide opportunities for mass casualties." Explicit admission of this target strategy has since come from Khalid Sheikh Mohammed, the Al Qaeda chief of military operations, who was arrested in March 2003.

One counterintuitive outcome of such a game is that the risk to very high-profile buildings, which are assumed to be highly attractive to the terrorist, could be much the same as the risk to buildings of less prominence, or value (Major, 2002). The more valuable the target, the more resources would be allocated to its defense. While the marginal effectiveness of increased defenses at any given target diminishes as the total defense resource allocation to that target increases, the terrorist's probability of success is still reduced. So if such a defense strategy is observable by terrorist groups, that target now a less attractive one to attack. Thus expected loss may actually be equalized across (valuable) targets.

The severity of the attack is a function of the attack mode, or weapon type. The likelihood that any particular weapon type will be utilized in an attack is a function of the organization carrying out the attack. It is also a function of target type. That is, the type of weapon selected in carrying out an attack will presumably be appropriate to the type of target given that the terrorist is constrained by limited resources. The probabilities assigned to weapon types are again developed in conjunction with input from the expert teams.

Modeled weapon types include so-called "conventional weapons", such as package, car and truck (of various sizes) bombs, as well as aviation crash. In light of Al Qaeda's 
clearly expressed interest in acquiring and deploying weapons of mass destruction, models also account for the possibility of "non-conventional" weapon attacks, including chemical, biological, radiological and nuclear (CBRN).

\subsection{Inventory Module}

The property databases that are used as input into natural catastrophe models are also relevant for terrorism models ${ }^{20}$. The attacks of September 11, 2001, revealed that not only are the terrorist targets themselves at risk, so are surrounding buildings. Nevertheless, the effects of terrorist attacks with conventional weapons are likely to be highly localized relative to hurricanes, earthquakes and the like. In that case, the resulting damage depends on such things as the kind explosive material used, the amount of material, and the density and verticality of the surrounding buildings.

For non-conventional weapons, the spatial extent of damage depends, for example, on the delivery mechanism, and on external factors such as wind speed and wind direction. Terrorism models can also be used to estimate aggregate insured or insurable losses for the entire insurance industry, for individual company portfolios, or for individual buildings. As in the case of natural catastrophe models, the quality of the output is only as good as the quality of the input data. As noted in the introduction, while the large losses resulting from natural catastrophes have historically been primarily to property, terrorist attacks can affect multiple insurance lines, including life, liability, workers' compensation, accident and health. They can also result in severe stress on the psyche of a nation under siege.

Modelers have access to or have developed industry databases of employees by building occupancy and construction type at ZIP Code level. These can be supplemented with state payroll and benefit information, generally available to insurance companies. The more detailed the information provided by the client, the more detailed and reliable the output. Modelers are emphasizing to insurers the importance of gathering detailed data on where people are during the day and in what kinds of buildings.

\subsection{Vulnerability}

Research on the impact of attacks on structures has been ongoing since before the 1950s. Much has been carried out by the Department of Defense. The Department of State has examined blast loading in the course of developing anti-terrorism designs for U.S. embassies. Other applications have had a civilian focus, such as examinations of the effects of natural gas explosions. Research activity has surged since the bombing of the Alfred P. Murrah Federal Office Building in Oklahoma City (1995) and the U.S. military housing facilities in Dhahran, Saudi Arabia (1996).

Modelers have developed damage functions that incorporate the results of experimental and analytical studies of how different building types respond to such attacks, combined with historical data from actual events. In the case of a terrorist attack using conventional and nuclear weapons, buildings sustain damage as a result of a variety of assaults on their structural integrity and their non-structural components. In the case of other non-conventional weapons, including chemical and biological, the structure of the building may be unaffected. The resulting contamination, however, may render it unusable for long

\footnotetext{
${ }^{20}$ See Grossi and Kunreuther (in press) for a detailed discussion of the elements of these databases.
} 
periods and result in extensive cleanup costs, up to full replacement value. In either case, the damage functions determine loss to building, contents and loss of use.

\section{Conventional Weapons}

The damage relationships that correspond to the building that is the "target" of the attack are functions of building type and attack type. The type of attack, whether package, car or truck bomb, can be expressed as a TNT-equivalent (trinitrotoluene). The size of this charge can be thought of as the "intensity" of the event. Damage to the target building results from the resulting shock wave, the subsequent pressure wave, and fire.

The target building may sustain "total" damage from the point of view of insured loss even if it remains standing. If the building collapses it will increase the number of fatalities. Furthermore, different modes of collapse, such as an overturn versus a "pancake" collapse as occurred at the World Trade Center in New York on 9/11, will affect the degree of damage to surrounding buildings and thus the total area affected by the event. The buildings surrounding the target building are also likely to be damaged by the resulting shock and pressure waves. In addition, they can be damaged by falling debris (the geographical extent of which depends on the mode of collapse, if any), and by flying (projectile) debris.

\section{Non-conventional Weapons (CBRN)}

The effects of nuclear weapons on both structures and populations have been the subjects of extensive research for decades. Chemical, biological and radiological (CBR, socalled "dirty bomb") attacks are more problematical. Accidental releases of chemical agents, such as the one that occurred at the Union Carbide chemical plant in Bhopal, India (1984) have been analyzed, as was the 1986 accident at the Chernobyl nuclear power plant, which resulted in a significant release of radioactive material. Other events include the 1995 sarin attack on the Tokyo subway and the more recent distribution through the mail of weaponized anthrax in autumn 2001 in the US. These examples provide data for empirical analysis and research.

Fortunately, those attacks have been extremely rare. The greatest degree of uncertainty associated with terrorist attacks surrounds the potential effects of nonconventional weapons. Modelers have, in some cases, developed relationships between the use of non-conventional weapons and potential damage; others employ models developed for various government agencies. These typically follow what is known as a "source/transport/effects" approach.

The source refers to how a hazard agent originates, including the type, yield, effectiveness, and other properties of the agent. Various attack types are simulated, including chemical agents such as sarin, VX, tabun, and biological agents such as anthrax and smallpox. Various types of nuclear and radiological attacks using materials such as cesium, cobalt and plutonium are also simulated.

Transport refers to the means by which the agent disperses or moves from the source to the people, or facilities, which are presumed to be the targets of the agent. A full range of dispersal mechanisms is considered, from mail-borne dispersal similar to the anthrax attacks in 2001, to wide area dissemination via aerosol spraying, and by way of conventional bomb blast. An important feature is the model's capacity for modeling winds over complex terrain. 
Effects refer to the physical, performance, and psychological effects of the attack on humans as well as on the environment. While even a small "suitcase" nuclear device can cause extensive physical damage to buildings over a relatively large geographical area, the primary effects on buildings of other non-conventional weapons is contamination, which may render them unusable for long periods of time. In fact, in some cases, the most cost-effective way of dealing with badly contaminated structures may be demolition under very cautious and well-defined procedures.

\subsection{Estimating Injuries and Fatalities}

In addition to property damage, terrorism models for insurance purposes also estimate fatalities under both workers' compensation and life insurance policies, as well as losses from injuries arising from workers' compensation, personal accident and other casualty lines. The number of injuries and fatalities, as well as the severity of injuries, is a function of the nature of damage sustained by both structural and non-structural components of buildings, and by their contents. Figure 3 illustrates the process for workers' compensation losses.

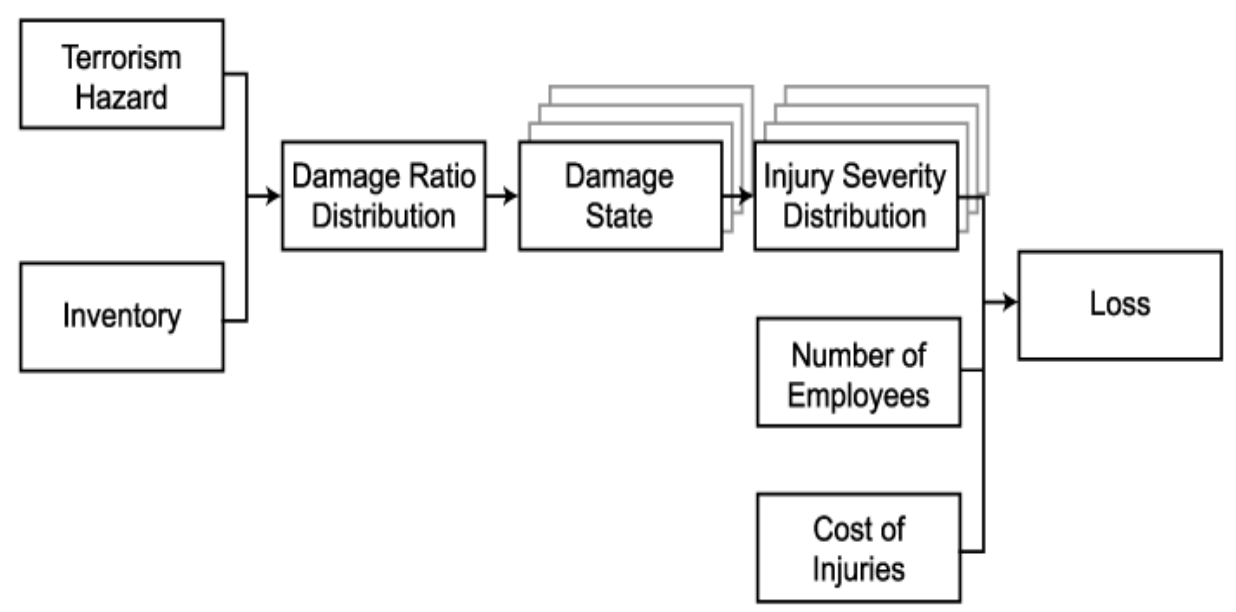

Figure 3. Modeling Worker's Compensation Losses

In estimating workers' compensation losses, the model accounts for variability in damage to individual buildings so that one can estimate the extent of injuries and fatalities. For each level of event severity, a mean damage ratio is calculated. Around each mean, a complete probability distribution of damage is developed. Because different structural types will experience different degrees of damage, the damage functions vary according to construction materials and occupancy. The distributions of damage are mapped to slight, moderate, extensive and complete in Figure 4. 


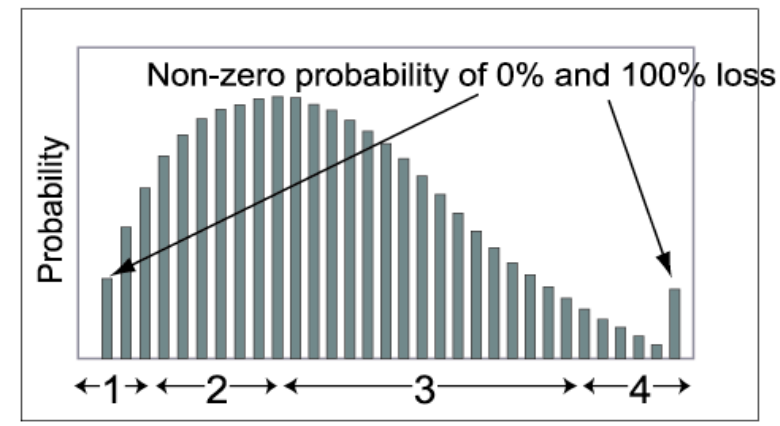

$$
\begin{aligned}
1 & - \text { Slight Damage } \\
2 & - \text { Moderate Damage } \\
3 & - \text { Extenstive Damage } \\
4 & - \text { Complete Damage } \\
& - \text { collapse } \\
& - \text { no collapse }
\end{aligned}
$$

Figure 4. Building Damage Distribution Mapped to Different Damage States

At the level of "complete" damage, the building may or may not have actually collapsed. Complete damage means that the building is not recoverable. Collapse would typically result in more severe injuries and larger numbers of fatalities than if the building is still standing. Once again, construction type is important: the probability of collapse given a state of complete damage may vary a lot by construction type.

Estimates of workers' compensation (and other casualty lines) loss are based not only upon the number of people injured, but also on the severity of the injuries. The HAZUS ${ }^{\circledR 21}$ model, for example, uses a four-tier severity scale: minor, moderate, life-threatening and fatality. Distributions of injury severity are then developed for each damage state for each building and occupancy type.

Combining information on the number of employees in each damaged building and the cost of injuries, the model generates the total loss distribution at a particular building. Figure 5 illustrates the flow of the calculations after the injury severity-rate distributions are determined. Losses are calculated based on the number of employees in each injury severity level and on the cost of the injury.

To calculate losses arising from life insurance and personal accident claims, the model takes the same approach described above, but potential losses are calculated for both residential and commercial buildings using assumptions about the distribution of the population between commercial and residential structures at the time of the attack.

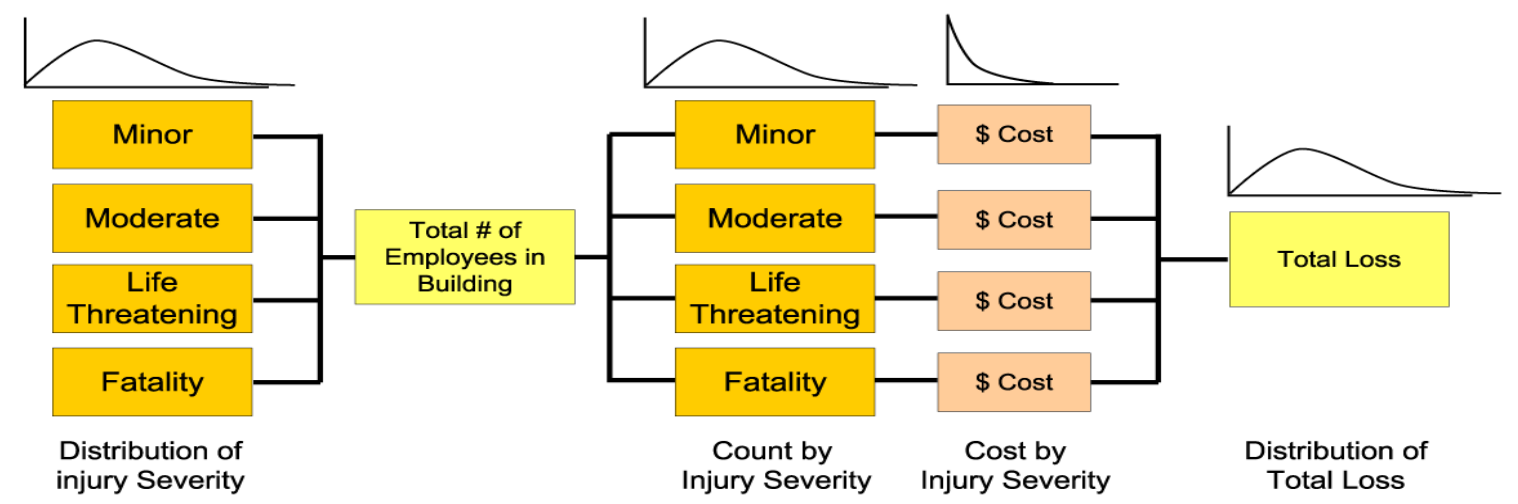

Figure 5. Calculation of Workers' Compensation Loss for an Individual Building

${ }^{21}$ HAZUS or Hazards U.S., is a natural hazard loss estimation methodology developed by FEMA under contract with the National Institute of Building Sciences. 


\subsection{The ISO Advisory Loss Costs}

Loss estimates generated by modeling techniques are of interest to all parties. Insureds want a better understanding of their exposure to potential terrorist attacks in order to determine whether to purchase coverage. Insurers can use model output to develop pricing, determine reinsurance needs and fashion policy conditions, including deductibles, exclusions and caps. Loss estimates for individual addresses can be of significant interest when the location, type of activity conducted at the address, or the prominence of the tenant may make that property a particularly attractive target. Model output is also of interest to policy makers. In New York, for example, modeled loss estimates are being used to support a request for a larger share of federal funding for homeland security.

Because terrorism models have been applied to thousands of potential targets, they can provide a picture of the relative risk by state, city, zip code and even by individual location. For example, at the start of 2002, the Insurance Services Office (ISO) used the estimates provided by AIR (one of its subsidiaries) to file advisory loss costs with the insurance commissioner for each state. ${ }^{22}$ ISO defined three tiers for the country. ISO's study placed Washington, DC, New York, Chicago and San Francisco in the highest tier and recommended loss costs in those cities of $\$ 0.10$ per $\$ 100$ of property value. A second tier consisted of Boston, Houston, Los Angeles, Philadelphia and Seattle; the rest of the country fell into the third tier.

ISO's recommendations were not, however, well received by cities in the first tier who felt they were being treated unfairly and some of whose politicians complained that such premiums would drive out businesses. Negotiations ensued and compromises made. ISO filed revised loss costs for first-tier cities based on zip code level model results, which differentiated between the higher risk of downtown city centers and the lower risk of properties on the outskirts. But nowhere did the new advisory lost costs exceed $\$ 0.03$ per $\$ 100$ of property value. ${ }^{23}$ Thus, while the new official advisory loss costs no longer adequately reflected the risk in the eyes of the modelers, they became more palatable for a number of stakeholders. The Departments of Insurance of all 50 states eventually approved ISO's 2003 loss costs. A revised scale for 2004 is now being filed.

\section{Future Public-Private Partnerships}

This section discusses the potential role of terrorist catastrophe bonds and summarizes the experience in other countries as to how the public and private sectors have established partnerships for covering terrorism risk. These arrangements may be appropriate for developing the future program of terrorism insurance in the United States after December 31,2005 . That question is explored in the last part of the section.

\footnotetext{
${ }^{22}$ A "loss cost" is defined by ISO as the long-term average annual expected loss (as generated by the AIR model) per $\$ 100$ of insured property value. It is used to set insurance rates, or premiums, after the addition of such things as an expense load to cover administrative fees, a profit margin, and a risk load. Once an ISO advisory loss cost has been approved by a state, any insurance company can adopt it without having to undertake their own often lengthy and expensive rate filing process.

${ }^{23}$ The second tier settled at $\$ 0.018$ per $\$ 100$ of property value and third tier at $\$ 0.001$.
} 


\subsection{Expanding Capacity Through Catastrophe Bonds}

One of the reasons why insurers have been reluctant to provide terrorist coverage is the lack of capacity by the insurance industry to cover this event. Cummins, Doherty and Lo (2002) have undertaken a series of analyses that indicate that the U.S. property-liability insurance industry could withstand a loss of $\$ 40$ billion with minimal disruption of insurance markets. According to their model, a $\$ 100$ billion loss would create major problems for the insurance industry by causing 60 insolvencies and leading to significant premium increases and supply side shortages.

As pointed out above, in the aftermath of $9 / 11$ there was a severe shortage of reinsurance against terrorism. For insurers to provide their clients with the same amount coverage they offered prior to $9 / 11$, they need to find capital from other sources. If the cost of this capital is high, the insurance premium will be prohibitively expensive and demand for coverage will dry up. To illustrate this point, it is useful to focus on the following scenario (with fictitious names) ${ }^{24}$

Over the past 10 years the AllRisk (AR) Insurance Company has provided \$500 million in coverage to Big Business (BB) Inc. against risks to its building, including those due to terrorism at a total premium of $\$ 13$ million. AR covers $\$ 100$ million itself and has purchased an excess of loss reinsurance contract from Reinsurance Enterprise (RE) to cover the remaining $\$ 400$ million. Given the events of Sept. $11^{\text {th }} \mathrm{RE}$ has decided that terrorism will no longer be included in its coverage because of the uncertainties associated with the risk. BB needs terrorism coverage since the bank that holds its mortgage requires this as a condition for the loan.

Now that RE has decided to eliminate terrorist coverage in its reinsurance treaties, AR must decide whether or not to continue providing BB with the same type of insurance as it has had previously and, if so, how much coverage it is willing to offer and at what price.

The first concern of the underwriters at AR is making sure the firm's chance of insolvency is below an acceptable risk level. For AR to offer BB $\$ 500$ million in coverage, it now has to raise an additional $\$ 400$ million in capital from different sources. One possibility would be for an investment bank to issue AR a $\$ 400$ million catastrophe bond to cover the losses from a potential terrorist attack. A catastrophe bond requires the investor to provide money up-front that will be used by the firm if some type of triggering event occurs, such as a terrorist attack. In exchange for a higher return than normal, the investor faces the possibility of losing either a portion of or its entire principal invested in the catastrophe bond.

The amount paid out to the insurance company (in this case AR) depends on how the catastrophe bond is constructed in advance of the event. If investors are concerned with the ambiguity associated with the terrorist risk, they will require a much larger than average return on their investment in order to compensate them for the possibility of losing their principal. Given the unusually high premiums on catastrophe bonds for natural hazard risks where there is considerably less ambiguity and uncertainty than for a terrorist attack, this should not be surprising.

One can now determine the premium that AR would have to pay for terrorist coverage as a function of the annual return on investment (ROI) required by investors for them to put money in a catastrophe bond. Assume that the normal annual return on

${ }^{24}$ This scenario is based on Kunreuther (2002). 
investments is $8 \%$. For a specific ROI, the annual cost, $\mathrm{C}$, to AR of obtaining $\$ 400$ million through issuing a catastrophe bond would be:

$$
(\mathrm{ROI}-0.08) \$ 400=\mathrm{C}
$$

If AR believes the probability of a claim of $\$ 100$ million is 0.01 then its actuarial loss for providing $\mathrm{BB}$ with this amount of insurance is $\$ 1$ million. Assuming a loading factor of $\lambda_{\mathrm{AR}}=0.5$ for $\mathrm{AR}$ to offer $\mathrm{BB}$ Inc. $\$ 500$ million of insurance coverage by purchasing a catastrophe bond for $\$ 400$ million, they would have to charge an annual premium (in millions of $\$ \mathrm{~s})$ of $\mathrm{P}=(\$ 1+\mathrm{C})(1.5)$.

Table 3 shows how $\mathrm{C}$ and $\mathrm{P}$ are affected by different required ROIs of investors.

Table 3. Impact of Changes in Return on Investment (ROI) on Catastrophe Bond Cost (C) and Insurance Premiums (P) (in Millions of \$)

\begin{tabular}{|c|c|c|}
\hline ROI & $\begin{array}{c}\text { Catastrophe Bond } \\
\text { Cost }(\mathbf{C})\end{array}$ & Premium (P) \\
\hline $10 \%$ & $\$ 8$ & $\$ 13.5$ \\
\hline $12 \%$ & 16 & 25.5 \\
\hline $14 \%$ & 24 & 37.5 \\
\hline $16 \%$ & 32 & 49.5 \\
\hline $18 \%$ & 40 & 61.5 \\
\hline $20 \%$ & 48 & 73.5 \\
\hline
\end{tabular}

During the fall of 2001, it was not unusual for investors to require an ROI of $20 \%$ to invest in terrorist coverage. ${ }^{25}$ In 2003, it is likely that the ROI for investors is lower than at the end of 2001; however, even if the ROI were only $12 \%$, insurers would have to charge $\$ 25.5$ million for terrorist coverage, almost twice the price that BB was paying prior to $9 / 11$.

\subsection{Potential Role of Terrorist Catastrophe Bonds}

It is interesting to speculate as to why a market for catastrophe bonds to cover losses from terrorist attacks has not emerged since 9/11. Consider the case where an investment banker was considering issuing a one-year catastrophe bond for covering the losses from terrorism. ${ }^{26}$ Let $p$ represent a conservative estimate of the probability of a terrorist attack during the year 2004 that would destroy BB's building.

If the normal annual rate of return was assumed to be $8 \%$ (i.e., 0.08 ), a risk neutral investor who committed $\$ Y$ to a catastrophe bond would require the following ROI when there was no terrorist attack:

$$
(1-p)(\mathrm{ROI}) \mathrm{Y}-p \mathrm{Y}=.08 \mathrm{Y}
$$

\footnotetext{
${ }^{25}$ This figure is based on discussions in November and December 2001 with insurers who were trying to raise capital for covering terrorist risks.

${ }^{26}$ We have focused on one-year catastrophe bonds to keep the example simple. Multi-year catastrophe bonds make the analysis more complicated but the qualitative conclusions discussed below do not change.
} 
Let $p_{i}$ be the annual probability of a terrorist attack where an investor is indifferent between receiving an annual $\mathrm{ROI}=i$ on a catastrophe bond knowing it would lose its entire investment should the attack occur. Substituting $i$ for ROI and $p_{i}$ for $p$ in equation (1) and rearranging terms one obtains:

$$
\mathrm{p}_{\mathrm{i}}=(\mathrm{i}-0.08) /(1+\mathrm{i})
$$

Thus, if $i=0.10$ one can determine from (2) that $p_{.10}=0.02 / 1.10=18 / 1000$. If a risk neutral investor believed the annual probability of a terrorist attack were $p<0.018$, then an ROI of $10 \%$ would be an attractive investment. If $i=0.20$ then $p_{.20}=0.12 / 1.20=1 / 10$ implying that if $p<0.10$, an individual would want to invest in a catastrophe bond if it returned $20 \%$ in the case of no terrorist attack. These indifference probabilities would be slightly lower if the investor were risk averse. Yet it is still hard to comprehend why the investment community has not viewed catastrophe bonds as a viable option for dealing with terrorism, particularly if a terrorist bond comprised only a small portion of the investor's portfolio.

In a recent paper, Bantwal and Kunreuther (2000) specified a set of factors that might account for the relatively thin market in catastrophe bonds in the context of natural hazard risks. They point out that spreads in this market are too high to be explained by standard financial theory, giving rise to another asset pricing puzzle that cannot be fully explained by investor risk aversion. The paper suggests that the high spreads are not just a consequence of investor unfamiliarity with a new asset, but instead signal some deeper issues that need to be resolved before the catastrophe bond market can fully develop. In particular, the authors conjecture that ambiguity aversion, myopic loss aversion, and fixed costs of education might explain the reluctance of institutional investors to enter this market.

Four additional factors may help explain the lack of interest in new financial instruments for covering the terrorist risk. There may be an important moral hazard problem associated with issuing such bonds if terrorist groups are connected with financial institutions having an interest in the U.S. Second, investment managers may fear the repercussions on their reputation of losing money by investing in an unusual and newly developed asset. Unlike investments in traditional high yield debt, money invested in a terrorist catastrophe bond can disappear almost instantly and with little warning. Those marketing these new financial instruments may be concerned that if they suffer a large loss on the catastrophe bond, they will receive a lower annual bonus from their firm and have a harder time generating business in the future. The short-term incentives facing investment managers differ from the long-term incentives facing their employers. If this is a major problem in marketing catastrophe bonds, then there is a need to develop strategies for bringing the principal (employer and its shareholders) and its agents (investment managers) into alignment.

A third reason why there has been no market for terrorist catastrophe bonds was the reluctance of reinsurers to provide protection against this risk following the World Trade Center attacks of September $11^{\text {th }}$. Investors (e.g., mutual funds) see reinsurers as experts in this market. When investors learned that the reinsurance industry required high premiums to provide protection against terrorism they were only willing to provide funds to cover losses from terrorism if they received a sufficiently high interest rate ${ }^{27}$.

\footnotetext{
${ }^{27} \mathrm{Jim}$ Ament provided us with this interesting insight.
} 
Finally most investors and rating agencies consider terrorism models to be too new and untested to be used in conjunction with a catastrophe bond covering risks in the United States. They are viewed by them as not very reliable in predicting the frequency of terrorist attacks, although they provided useful information on the potential severity of the attacks. One of the major rating firms noted that the estimates derived from the models could vary by 200 percent or more. Without acceptance of those models by the major rating agencies, the issuance of terrorist catastrophe bonds would be unlikely, at least in the United States.

(U.S. General Accounting Office, 2003). ${ }^{28}$.

\subsection{Experiences in Other Countries}

\section{United Kingdom}

In the wake of the two terrorist bomb explosions in the City of London in April 1992 and an announcement seven months later by British insurers that they would exclude terrorism coverage from their commercial policies, the UK established a mutual insurance organization (Pool Re) to accommodate claims following terrorist activities (Fleming, 1993). Pool Re charges a separate, optional premium for terrorism coverage that can be calculated as a percentage of the total sum insured under a fire and accident policy and mainly depends on the location of the property. The four different rates established by Pool Re are based on the risks, with the highest rate in Central London and the second highest in the rest of the city. The Treasury as the reinsurer of last resort backs Pool Re.

Until September 11, 2001 terrorism exclusions within insurance policies in the UK were usually limited to property policies. They were based on the Terrorism Act of 1993 and designed to deal with the IRA bombing campaign on mainland Britain. Fire and explosion were excluded by insurance companies, but were covered under Pool Re. The scale of 9/11 attacks in the US led to the need for an extending protection under Pool Re to "all risks" (including damage caused by chemical and biological as well as nuclear contamination, with effect on January 1, 2003). This extension in cover to all risks reflected in a doubling of the pre September $11^{\text {th }} 2001$ premiums charged by the pool. Moreover, insurers are now free to set the premiums for underlying terrorism policies, thereby introducing competition into the terrorist insurance market ${ }^{29}$.

\section{France}

France suffered several terrorist attacks during the 1980's. A law enacted in September 1986 requires the French insurers to provide terrorism coverage up to the overall limits of a property policy. To avoid problems of adverse selection and low demand for insurance that may result in large uncovered losses, terrorism insurance is mandatory in France. After 9/11 French insurers were forced to renew terrorist coverage and retain most of

\footnotetext{
${ }^{28}$ The first terrorism catastrophe bond was issued in Europe in August 2003. The world governing organization of association football (soccer), the FIFA, which organizes the 2006 World Cup in Germany, developed a bond to protect its investment. Under very specific conditions, the catastrophe bond covers natural and terrorist extreme events that would result in the cancellation of the final World Cup game. (U.S. General Accounting Office, 2003).

${ }^{29}$ There was also an intention to set the maximum insurance retention for the next four years, with individual insurers' retentions being based on market share. It is now set at $£ 30$ million (43 million euros) per event and $£ 60$ million (86 million euros) per annum for 2003; it will increase up to $£ 100$ million (144 million euros) per event and $£ 200$ million (288 million euros) per annum for 2006.
} 
the risk, as most reinsurers refused to cover acts of terrorism in their policies. Discussions between FFSA, GEMA ${ }^{30}$ and the French government led to the creation of the first post 9/11 State backed reinsurance pool for terrorism worldwide, the GAREAT (for Group of Insurance and Reinsurance against Terrorism, in French), on January 1, 2002. A premium scale is established nationwide that only depends on the sum insured and not on the location at risk. All insurers must be members of the pool. (Godard et al., 2002).

As of 2003, the current partnership between the government and the insurance industry is a four-layer scheme. Private insurers retain the first portion of losses up to 400 million euros; the next layer is placed in the international insurance and reinsurance market up to 1.5 billion euros (a 1.1 billion euros trench). A third layer is comprised of reinsurance covering losses between 1.5 and 1.75 billion euros. Losses greater than 1.75 billion euros are covered by the government (unlimited guarantee for which the pool pays an annual premium), and managed by the Caisse Centrale de Réassurance, a public-owned reinsurer. (Michel-Kerjan and Pedell, 2003).

\section{Germany}

Discussions between the German federal government and the insurance industry led to the creation of a special insurer for terrorism risks, Extremus AG. The company has been operating since November 2002. Extremus, which is a corporation whose shareholders are essentially private insurers and reinsurers operating in Germany, directly insures terrorism risk through the participating companies. As in France, a premium scale is established nationwide that depends on the sum insured and not on the location at risk ${ }^{31}$. Coverage by Extremus is only offered if the total insured value per policy is at least 25 million euros and it is non-compulsory.

As of 2003, the annual reinsurance capacity is limited to 13 billion euros and is provided in three layers. The shareholders of Extremus provide the first layer of 1.5 billion euros. International reinsurance companies provide the second layer of another 1.5 billion euros. The Federal Government of Germany would provide an additional capacity of 10 billion euros ${ }^{32}$.

\section{Israel}

The government administers two programs for dealing with terrorism risk. The Israeli Income and Property Tax Commission levies a national property tax predominantly on Israeli business. The Commission pays for claims on property damages from a terrorist attack, but indirect damages (including business interruption) must be covered by private insurance. The second government program, administered by the National Insurance Institute, provides for medical care, lost wages, payments to the families of attack victims and personal injury. (General Accounting Office, 2001).

\footnotetext{
30 The French Federation of Insurance Companies and the French Group of Mutual Insurance Firms, respectively; the two major representative institutions from the French insurance market.

${ }^{31}$ The idea here is that a larger chemical plant, for instance, may be a higher target whatever its location.

${ }^{32}$ For a comparative analysis of the current terrorism insurance schemes developed after 9/11 in the US, France and Germany (relative to each country's market), see Michel-Kerjan and Pedell (2003).
} 


\subsection{A Proposed Program for the United States}

Currently it is unclear what type of terrorism insurance program will emerge in the United States after 2005. One possibility is that TRIA will be renewed with a new risk sharing arrangement between the insurance industry and the federal government. However, if the program is terminated on December 31, 2005, alternative solutions will need to be found. The challenge is to develop an efficient program that will satisfy the different interested parties, each of whom has their own set of values and concerns. In addition to insurance coverage, there are ways of providing protection prior to an event, so as to reduce the need for the public sector to provide financial aid following a disaster. Federal funding provided to the airlines after 9/11 suggests that actions could be taken now rather than waiting until the next catastrophe occurs. Four elements of such a program are set forth below.

First, existing institutions, such as banks and financial institutions, could require terrorism coverage as a condition for loans and mortgages. By having these institutions protect their own investments, then those who are at risk will be eligible to receive insurance claims after a catastrophic event to aid their recovery process. Furthermore the potential costs of terrorism will be borne by those at risk ${ }^{33}$. For example, rents to tenants in commercial buildings may increase to reflect the extra cost of terrorist insurance coverage since 9/11.

Second, private insurer exposure to losses from terrorism could be limited so that coverage could be offered at reasonable rates. Insurers may want to require risk reduction measures as a condition for coverage. If insurers know that their losses from a terrorist attack will be capped at a certain amount, much of the uncertainty regarding the event will be reduced. Insurers will then focus primarily on the probability of certain events occurring rather than on the entire distribution of potential losses.

Third, the government could provide some type of federal catastrophe bond given the reluctance of private investors to provide capital to insurers and/or reinsurers and the high return they require on private catastrophe bonds. Such a federal program could be designed so that it does not discourage the private sector from entering the market.

Finally, solutions in other countries could be examined to see how well they are working in practice and whether some features would be appropriate for the United States. One option could be the creation of a pool arrangement between insurers and reinsurers with some type of federal role if the losses were extremely large. One may want to examine the performance of GAREAT created in France, the German Extremus, or the recent modifications established on January $1^{\text {st }}, 2003$ with Pool Re in the UK.

\section{Future ReSEARCh Directions}

This concluding section builds on the discussion of terrorism insurance to suggest future research for dealing with extreme events by focusing on two areas: Risk Assessment and Vulnerability Analyses and Risk Perception and Risk Management Strategies.

\subsection{Risk Assessment and Vulnerability Analyses}

Risk assessment needs to be supplemented by vulnerability analyses that characterize the forms of physical, social, political, economic, cultural, and psychological harms to which

\footnotetext{
${ }^{33}$ That question was already raised in the aftermath of the World War II in the context of war damage insurance to cover against nuclear weapons (Hirshleifer, 1953).
} 
individuals and modern societies are susceptible. Many millions of dollars have already been spent on a variety of actions that are designed to reduce vulnerability to terrorism.

As one moves from events where considerable historical and scientific data exist (e.g. earthquakes) to ones where there is greater uncertainty and ambiguity (e.g. terrorism), there is a much greater degree of discomfort in undertaking risk assessment. Constructing scenarios that may lead to the occurrence of specific events is a useful first step.

A meaningful example of work in this regard is a study undertaken over 25 years ago by Warner North and his colleagues on estimating the likelihood of microbial contamination of Mars from the first Viking Mission where a landing on the planet was planned on July 4, 1976. They first constructed a series of scenarios characterizing how microbes could contaminate Martian soil based on the possible location of microbes on the spacecraft and Martian environmental conditions. They then assigned probabilities of contamination to each of these scenarios and undertook extensive sensitivity analyses to determine how changes in the inputs to these scenarios would lead to changes in these probabilities. On the basis of these analyses they determined that the probability of contamination was more than one order of magnitude below the predetermined acceptable level of risk of 1 in 10,000. Scientists who had initially expressed concern about the risk of contamination agreed that the mission should proceed without the need for further steps to reduce the microbial burden on the Viking Lander. The Viking successfully landed on Mars in the summer of 1976.

\subsection{Risk Perception and Risk Management Strategies}

The terrorist attacks of $9 / 11$ have raised the question as to what one should do to mitigate the consequences of future catastrophes and aid the recovery process should another disaster occur. In order to develop a strategy, one needs to incorporate the growing knowledge of how individuals process information on extreme events and then make choices.

As illustrated by the examples of Hurricane Andrew and the Northridge earthquake, people are not very concerned about the possibility of catastrophe events before they occur. Only after the event, when it is often too late, do they want to take protective action. Moreover, this concern dissipates over time. Thus, it is very common for people to cancel their flood or earthquake insurance policies if they have not experienced losses from one of these events for several years.

To mitigate against the consequences of natural disasters safer structures can be built and/or people can move out of harm's way. In the case of chemical accidents, the inventory level and/or production of specific toxins can be reduced to lower the risk of another mishap occurring. When it comes to developing a strategy to reduce the risks of future terrorist activities, considerable uncertainty exists with respect to who the perpetrators are, their motivations, the nature of their next attack and where it will be delivered. Terrorist groups can attack anything, anywhere at any time, and one cannot protect everything. Hence, as we discussed above, it is extraordinarily difficult to know what efficient protective actions to take.

There is an additional challenge associated with allocating resources for dealing with terrorism. The government may be tempted to invest huge sums of money in protection to provide reassurance for its citizens (reassuring expenditures). Educating the public on the current likelihood of attacks might reduce such costs. 
Future research should also address the appropriate strategies that need to be developed for dealing with situations where there are interdependencies between agents. In these situations there may be a need for the public sector to take the leading role with respect to providing protective measures because the private sector may have few economic incentives to take these steps on their own. Kunreuther and Heal (2003) and Heal and Kunreuther (2003) have addressed this issue by asking the following question: What economic incentives do residents, firms or governments have for undertaking protection if they know that others are not taking these measures and that their failure to do so could cause damage to them?

To illustrate this point, suppose Airline A is considering whether to institute a sophisticated passenger security system knowing that passengers who transfer from other airlines may not have gone through a similar screening procedure and could cause damage to their airplane. If there is a relatively high probability that these dangerous passengers could get on board Airline A due to the failure of other airlines to adopt screening systems and there is no screening process for passengers who transfer from one airline to another, then Airline A will also not want to invest in such a system. The interdependent risks across firms may lead all of them to decide not to invest in protection.

The same logic applies to the incentive of divisions of firms to invest in protection against a catastrophic accident that could bankrupt the entire organization. The actions of Nick Leeson and the traders he hired at the Barings Futures Singapore office were primarily responsible for bringing down Barings Bank. Arthur Andersen was sent into bankruptcy mainly by the actions of its Houston branch. If a division knows that other divisions in the firm are not investing in protection or in good risk management, then it has less incentive to incur these costs than if the other units were investing in safety measures. This is another example of interdependent risks (Kunreuther, 2003).

The 9/11 events, as well as the anthrax attacks, also demonstrated a new kind of vulnerability: terrorists can use the capacity of a country's infrastructures to have immediately a large-scale impact on the nation by reversing the diffusion capacity of our own networks against ourselves ${ }^{34}$, each element of the network becoming at risk, a potential weapon (every aircraft, every piece of mail). Those are crucial questions as the large operating networks of the country (water supply, electricity ${ }^{35}$, transportation networks, telecommunications, energy, emergency and defense services, etc $^{36}$ ) become more and more interdependent with each other when, at the same time, the social and economic continuity of a nation's activities critically depend on their operation (Michel-Kerjan, 2003; OECD, 2003; White House, 2003).

The development of public-private partnerships is clearly recognized as a way of decreasing the vulnerability of infrastructures. As discussed in section 2.2, the question of information sharing may constitute, however, one of the main limitations to the development

\footnotetext{
${ }^{34}$ During the anthrax episode, for example, the terrorists did not attack a specific postal office but used the whole USPS network itself to spread threats. Indeed, in that case, the whole network was potentially at risk as any envelope could have been considered as contaminated by anthrax, a potential weapon (Boin, Lagadec, Michel-Kerjan and Overdijk, 2003). The emerging vulnerabilities in critical infrastructures raise some of the most challenging questions related to mitigation of terrorism and interdependencies.

${ }^{35}$ As illustrated by the August 14, 2003 power failure in the U.S. and the September 27, 2003 one in Italy.

${ }^{36}$ In 1998, U.S. Presidential Decision Directive 63 classified those sectors, among others, as "critical infrastructure sectors" for the social and economic continuity of the country.
} 
of such partnerships. What type of information could government agencies actually share regarding ongoing threats with the private sector without violating national security rules? Conversely, as nearly $85 \%$ of critical infrastructures is owned or operated by the private sector in the U.S., private firms have obtained considerable information about the infrastructures themselves, the level of security as well as their clients. What are the incentives for the private sector to share such sensitive information with government agencies? What specific risk-sharing rules or schemes will emerge from a specific distribution of information about risks between all the interested parties of a public-private partnership?

Future research should examine these questions in more detail as well as the appropriate role of regulations, standards, third party inspections and insurance to encourage individuals and firms to take protective actions. Without some type of coordinating mechanism or economic incentive such as a fine, subsidy or tax it may be difficult to convince any individual agent to invest in mitigation because they know they may be contaminated by others. By developing public-private partnerships to deal with interdependencies associated with extreme events, one should be able to provide substantial benefits to the affected individuals and firms as well as improving the social welfare. 


\section{REFERENCES}

Adler, Michael and Ziglio, Erio (eds) (1996) Gazing Into the Oracle: The Delphi Method and Its Application to Social Policy and Public Health London, Kingsley Publishers.

Bantwal, Vivek and Kunreuther, Howard (2000) “A Cat Bond Premium Puzzle?", Journal of Psychology and Financial Markets, 1:76-91.

Boin, Arjen, Lagadec, Patrick, Michel-Kerjan, Erwann and Werner Overdijk (in press) "Critical Infrastructures under Threat: Learning from the Anthrax Scare" Journal of Contingencies and Crisis Management.

Brown, Jeffrey, Kroszner, Randall and Jenn, Brian (2002) "Federal Terrorism Insurance" NBER Working Paper 9271, Cambridge, MA, October 2002.

Cauley, Jon and Im, Eric Iksoon (1988) "Intervention Policy Analysis of Skyjackings and Other Terrorist Incidents" American Economic Review, 78 (2): 27-31.

Council of Insurance Agents and Brokers (2003) "Commercial Market Index Survey" News Release, July 22 .

Council of Insurance Agents and Brokers (2003) "Many Commercial Interests Are Not Buying Terrorism Insurance, New CIAB Survey Show" News Release, March 24.

Cummins, J. David, Doherty, Neil and Lo, Anita (2002) "Can Insurers Pay for the 'Big One?' Measuring the Capacity of an Insurance Market to Respond to Catastrophic Losses." Journal of Banking and Finance, 26: 557-583.

Cummins, J. David and Doherty, Neil (2002) "Federal Terrorism Reinsurance: An Analysis of Issues and Program Design Alternatives" Paper Presented at the NBER Insurance Project Workshop, Cambridge Mass. Feb. 1.

Eeckhoudt, Louis and Gollier, Christian (1999) "The Insurance of Low Probability Events" Journal of Risk and Insurance, 66: 17-28.

Enders, Walter and Todd, Sandler (2000) "Is Transnational Terrorism Becoming More Threatening Journal of Conflict Resolution, 44 (3): 307-332.

Enders, Walter and Todd, Sandler (1993) "The Effectiveness of Anti-terrorism Policies: A VectorAutoregression-Intervention Analysis” American Political Science Review, 87 (4): 829-844.

Fleming, Alan (1993) "The Role for Pool Re", Proceedings of Property Owners, Insurance Conference: Problems and Solutions, pp. 35-40.

Froot, Kenneth. (ed.) (1999) The Financing of Catastrophe Risks. Chicago: University of Chicago Press.

Godard, Olivier, Henry, Claude, Patrick Lagadec and Erwann Michel-Kerjan (2002) Treatise on New Risks. Sustainability, Crisis, Insurance (in French). Paris: Editions Gallimard.

Gollier, Christian (2000) "Towards an Economic Theory of the Limits of Insurability" Assurances, January, pp.453-474. 
Grace, Martin, Klein, Robert, Kleindorfer, Paul and Michael, Murray (2003) Catastrophe Insurance. Consumer Demand, Markets and Regulation. Boston: Kluwer Academic Publisher.

Grossi, Patricia and Kunreuther, Howard (eds.) (in press) New Approaches to Managing Risks from Natural Hazards. Norwell, MA: Kluwer Academic Publishers.

Hale, D (2002) “America Uncovered” Financial Times, September 12.

Hartwig, Robert (2002) "September 11, 2001: The First Year. One Hundred Minutes of Terror that Changed the Global Insurance Industry Forever”. Insurance Information Institute.

Heal, Geoffrey and Kunreuther, Howard (2003) "You only die once: managing discrete interdependent risks." NBER Working Paper 9885, Cambridge, MA, July 2003.

Hirshleifer, Jack (1953) “War Damage Insurance”, Review of Economic Studies, 35(2): 144-153.

Hoffman, Bruce (1998) Inside Terrorism. New York: Columbia University Press.

Hsu, Spencer (2003) “D.C. Disputes Insurance Study Raising Rates For Terrorism” Washington Post, January 7, page A01.

Jaffee, Dwight and Russell, Thomas (2002) "Extreme Events and the Market for Terrorism Insurance": Paper Presented at the NBER Insurance Project Workshop, Cambridge Mass. Feb. 1.

Keohane, Nathaniel and Zeckhauser, Richard (2003) "The Ecology of Terror Defense" Journal of Risk and Uncertainty, 26(2/3), 2003, 201-229.

Kleindorfer, Paul and Kunreuther, Howard (1999) "Challenges facing the Insurance Industry In Managing Catastrophe Risks" in The Financing of Catastrophe Risks, edited by Ken Froot, Chicago: University of Chicago Press.

Kunreuther, Howard (2003) "The pitfalls of an interdependent world" Financial Times, August 28, p.11.

Kunreuther, Howard and Heal, Geoffrey (2003) "Interdependent Security" Journal of Risk and Uncertainty, 26(2/3): 231-249.

Kunreuther, Howard (2002) "The Role of Insurance in Managing Extreme Events: Implications for Terrorism Coverage" Risk Analysis, august 2002, 22: 427-437.

Kunreuther, Howard, Jacqueline Meszaros, Robin Hogarth, and Mark Spranca (1995) "Ambiguity and underwriter decision processes" Journal of Economic Behavior and Organization, 26:337-352.

Lelain, Patrick, Bonturi, Marcos and Koen, Vincent (2002) "The Economic Consequences of Terrorism" OECD Working paper 334, Department of Economics, Paris: OECD.

Linstone, Harold and Turoff, Murray (1975) The Delphi Method. Techniques and Applications. Addison-Wesly Publishing Company.

Major, John (2002) “Advanced Techniques for Modeling Terrorism Risk" Journal of Risk Finance 4 (1):15-24.

Michel-Kerjan, Erwann (2003) "New Vulnerabilities in Critical Infrastructures: A US Perspective" Journal of Contingencies and Crisis Management 11 (3): 132-140. 
Michel-Kerjan, Erwann and Pedell, Burkhard (2003) "Terrorism Risk Coverage after 9/11: A Comparison of the New Public-private Partnerships in France, Germany and the U.S.", working paper, Philadelphia: Center for Risk Management and Decision Processes, The Wharton School, in preparation.

Muto, Sheila (2003) “Lighthouse Battle Starts New Chapter", Wall Street Journal, October 8.

Organisation for Economic Co-operation and Development (2003) Emerging Systemic Risks in the $21^{\text {st }}$ Century: An Agenda for Action. Paris: OECD.

Pate-Cornell, Elisabeth and Guikema, Seth (2002) "Probabilistic Modeling of Terrorist Threats: A Systems Analysis Approach to Setting Priorities Among Countermeasures" Military Operations Research 7:5-20. December.

Roth, Richard, Jr. (1998) "Earthquake Insurance Protection in California" Chap. 4 in Kunreuther Howard and Roth, Richard, Sr. (eds.) (1998) Paying the Price: The Status and Role of Insurance Against Natural Disasters in the United States, Washington, D.C: Joseph Henry Press.

Sandler, Todd and Enders, Walter (2004), "An Economic Perspective of Transnational Terrorism" European Journal of Political Economy, forthcoming.

Sandler, Todd, Tschirhart, John and Cauley, Jon (1983) "A Theoretical Analysis of Transnational Terrorism" American Political Science Review, 77: 36-54.

Swiss Re (2002-a) Natural catastrophes and man-made disasters 2001: man-made losses take on a new dimension, Sigma No1, Zurich: Swiss Re.

Swiss Re (2002-b) Terrorism — dealing with the new spectre Zurich: Swiss Re, Feb.

Trajtenberg, Manuel (2003) "Defense R\&D Policy in the Anti-Terrorist ERA", NBER Working Paper 9725, Cambridge, MA, May 2003.

Treaster, Joseph (2003) "Insurance for Terrorism Still a Rarity" New York Times, March 8.

U.S. General Accounting Office (GAO) (2003) Catastrophe Insurance Risks. Status of Efforts to Securitize Natural Catastrophe and Terrorism Risk. GAO-03-1033. Washington, D.C.: September 24.

U.S. General Accounting Office (GAO) (2002) “Terrorism Insurance: Rising Uninsured Exposure to Attacks Heightens Potential Economic Vulnerabilities", Testimony of Richard J. Hillman Before the Subcommittee on Oversight and Investigations, Committee on Financial Services, House of Representatives. February 27.

U.S. General Accounting Office (GAO) (2001) "Terrorism Insurance: Alternative Programs for Protecting Insurance Consumers", Testimony of Thomas McCool Before the Committee on Banking, Housing and Urban Affairs, US Senate. October 24.

White House (2003) National Strategy for Physical Protection of Critical Infrastructures and Key Assets Washington, DC, February 2003.

White House (2002) National Strategy for Homeland Security Washington, DC, July 2002.

Woo, Gordon (2002) “Quantitative Terrorism Risk Assessment” Journal of Risk Finance, 4 (1): 7-14. 